\title{
İlerleyen Sansürlü Örneklemlere Dayalı Olarak Weibull Dağılımının Şekil Parametresinin Sağlam Tahmin Edicileri
}

\author{
Arzu Altın YAVUZ ${ }^{* 1}$ (1) \\ ${ }^{1}$ Eskişehir Osmangazi Üniversitesi, Fen Edebiyat Fakültesi, İstatistik Bölümü, 26480, Eskişehir, Türkiye
}

(Alınış / Received: 17.02.2021, Kabul / Accepted: 08.03.2021, Online Yayınlanma / Published Online: 15.08.2021)

\author{
Anahtar Kelimeler \\ İstatistik, \\ Güvenilirlik analizi, \\ Weibull dağılımı, \\ İlerleyen sansürlü örneklem, \\ Sağlam tahmin edici
}

\begin{abstract}
Özet: Yaşam modellerinde parametre tahmini oldukça önemli bir konudur. Uygulamada karşılaşılan veri tipi genellikle ilerleyen sansürlenmiș veri şeklindedir. İlerleyen sansürlü örneklemlere dayalı parametre tahmini, klasik tam örneklem durumundan farklıdır. Bu çalışmanın amacı ilerleyen sansürlü veriye dayalı olarak Weibull dağılımının şekil parametresini tahmin etmektir. Bu amaçla Weibull dağılımının şekil parametresi basit doğrusal regresyon modeli kullanılarak tahmin edilmiştir. Tahmin yöntemi olarak En Küçük Kareler (EKK) ve sağlam (robust) tahmin yöntemi olan M (Huber, Tukey ve Hampel) tahmin edicileri ele alınmıştır. Bu tahmin yöntemlerinin etkinlikleri veri setinin aykırı değer içerip içermeme durumuna göre Monte-Carlo simülasyon çalışmasıyla karşılaştırılmıştır. Sonuç olarak, ilerleyen sansürlü örnekleme dayalı olarak Weibull dağılımının șekil parametresinin tahmini için en etkili tahmin edicinin $\mathrm{M}$ tahmin ediciler olduğu belirlenmiştir.
\end{abstract}

\section{Robust Estimators of the Shape Parameter of Weibull Distribution Based on Progressively Censored Sample}

\section{Keywords}

Statistics,

Reliability analysis,

Weibull distribution,

Prograssive censored sample, Robust estimator

\begin{abstract}
Parameter estimation is a very important issue in lifetime models. The data type encountered in practice is usually in the form of progressive censored data. Parameter estimation based on progressive censored samples is different from the classical full sample case. The aim of this study is to estimate the shape parameter of the Weibull distribution based on the progressive censored sample. For this purpose, the shape parameter of the Weibull distribution was estimated using a simple linear regression model. Least Squares (OLS) and robust estimation method M (Huber, Tukey and Hampel) estimators are used as estimation method. The efficiencies of these estimation methods were compared with the Monte-Carlo simulation study according to whether the data set contains outliers or not. As a result, $\mathrm{M}$ estimators was determined as the most effective estimators for the estimation of the shape parameter of the Weibull distribution based on the progressive censored sample.
\end{abstract}

\section{Giriş}

Güvenilirlik çalıșmaları, ölüm, bozulma, çürüme gibi başarısızlık (failure) olarak adlandırılan olayların meydana çımmasına kadar geçen sürenin modellenmesi ile ilgilenmektedir. Güvenilirlik analizi tıp, mühendislik, sosyal bilimler ve sigortacılık gibi birçok alanda kullanılmaktadır. Günümüzde sistemlerin, alt sistemlerin ve bileşenlerin yaşam analizi önemli bir konudur [1].

Mühendislik alanındaki güvenilirlik çalıșmaları, sistemlerdeki arızaları ve onarımları araştırarak, arıza olasılığını ve güvenlik risklerini azaltmayı amaçlamaktadır. Buna bağlı olarak sistemin ömrü içerisindeki kullanılabilir zamanını artırmayı hedeflemektedir. Güvenilirlikle ilgili çeşitli tanımlamalar yapılmıștır. Güvenilirlik, bir ürünün kendinden beklenen uygulamaları belirli bir zaman periyodunda yeterli bir şekilde gerçekleştirme olasılığı olarak tanımlanmaktadır [1]. Ayrıca güvenilirlik, bir bileşenin, aygıt, ekipman veya sistemin belirli koşullar altında, belirli bir zaman periyodu için kendinden beklenen işlevleri gerçekleştirme olasılığı olarak ifade edilebilir [2]. Güvenilirlik, kalitenin zamana bağlı fonksiyonudur. 
Bu tanım, güvenilirliğin kaliteyle olan yakın ilişkisine vurgu yapmaktadır. Güvenilirlik ürünün çalışma sürecindeki performansıdır [3]. Genel olarak güvenilirlik, bir ürünün, parçanın ya da sistemin tanımlanmış olan görevini belirlenen bir zaman aralığında, tam olarak yerine getirme olasılığı olarak tanımlanmaktadır $[4,5]$

Günümüzde endüstriyel ve teknolojik gelişmelerin hız kazanmasıyla birlikte kesintisiz ve sorunsuz bir hizmet sağlama önemli bir amaç haline gelmiş ve güvenilirlik kavramı daha da önem kazanmıștır. Güvenilirlik analizinin temelinde yaygın olarak istatistik bilimi ve olasılık dağılımları yer almaktadır. Sistemlerin veya bileşenlerin bozulma ya da arızalanma sürelerini modellemek için olasılık dağılımları yaygın biçimde kullanılmaktadır $[4,6,7]$. Güvenilirlik analizinde, belirli bir zaman aralığında gerçekleşen hata sayıları için kesikli dağılımlar, zamana karşı dayanma süresi gibi herhangi bir değer alan değişkenleri modellemek için ise sürekli dağılımlar kullanılmaktadır [2]. Mühendislik yöntemleri ve istatistik bilimindeki gelişmeler sayesinde bir donanımın ya da sistemin güvenilirliğinin hesaplanması yani geçmişteki verilerin incelenerek geleceğe yönelik tutarlı ve doğru tahminlerde bulunulması konusundaki çalışmalar hız kazanmıştır.

Güvenilirlik analizinde en önemli unsur malzemenin, bireyin ya da bileşenin yaşam süresidir [2]. Yaşam süresinin dağılımı için literatürde yaygın olarak Weibull dağılımı kullanılmaktadır. Weibull dağılımı şekil parametresinin aldığı değere göre simetrik, pozitif ya da negatif çarpik verilerin modellenmesinde esneklik sağlamaktadır. Yaşam dağılımının parametre tahmini çalışmalarında yaygın olarak kullanılan tahmin yöntemleri; En Küçük Kareler (EKK), momentler, en çok olabilirlik ve Lmomentler tahmin yöntemleridir. Weibull dağılımının parametrelerini tahmin etmek için, farklı yazarlar tarafından çeşitli tahmin yöntemleri önerilmiştir [8-10]. Bunların arasında, En çok olabilirlik (EÇO), teorik açıdan en popüler olandır. Medyan Sıra Regresyon (MSR) yöntemi hesaplamalar için basit kapalı form çözümleri sunmaktadır. EÇO ve MSR arasındaki karşılaştırmalar bazı araştırmacılar tarafından yapılmıştır [11-14]. Tam örneklem durumu, Tip II ya da Tip I sansürlü örneklem durumu için birçok tahmin yöntemi simülasyonlarla karşılaştırılmıştır. Bununla birlikte, bu çalışmalar, çeşitli sansürleme seviyelerinde farklı veri üretme mekanizmalarıyla yapıldıkları için, bir yöntemin diğerine tercih edilmesine ilişkin çelişkili görüşlere yol açmıştır [15].

İlerleyen sansürlü örneklem durumunda parametre tahmini için genellikle EÇO tahmin edicileri ya da parametrik olmayan tahmin ediciler kullanılmıștır. Cacciari ve Montanari [16], bazı parametrik olmayan yöntemler ile EÇO tahmin edicilerini farklı örneklem hacimleri ve sansürleme oranlarıyla karşılaştırmıştır. Montanari ve ark. [17], sansürlenmiş veriler için küçük örneklem hacimlerinde EÇO tahmin edicilerini $\% 30$ ve $\% 50$ sansürleme oranında yanlılıkları bakımından karşılaştırmışlardır. NG ve ark. [18], Weibull dağılımı için optimal ilerleyen sansürlü örneklem planı önermişlerdir. Zhang ve ark. [19], Weibull dağılımının şekil parametresi için aykırı gözlem içeren tam örneklem durumunda sağlam M tahmin edicilerini önermişlerdir. Boudt ve ark. [20], tam örneklem durumunda Weibull parametreleri için sağlam tahmin ediciler önermişlerdir. Olteanu ve Freeman [21], sağdan sansürlü veriler için Weibull dağılımının EÇO ve MSR tahmin edicilerini büyük örneklem hacimleri için karşılaștırmıșlardır. Genschel ve Meeker [22], tip I ve tip II sansürlü veri durumunda Weibull dağılımının EÇO ve MSR tahmin edicilerini MSE ve LOSS kriterleri bakımından karşılaştırmışlardır. Asgharzadeh ve ark. [23], ilerleyen sansürlü örneklemlere dayalı olarak Weibull dağılımının stres-dayanıklılık modelinin güvenirliliği için tahmin yöntemlerini önermiș ve karşılaştırmışlardır. Mohan ve ark. [24], Weibull dağılımının EKK ve MSR tahmin edicilerini tam örneklem durumunda karşılaştırmışlardır. Tüm bu yöntemlerde etkin sonuç elde etmek için örneklem hacminin oldukça büyük olması gerekmektedir. Oysa ki güvenilirlik çalışmalarında maliyet ve zaman gibi kısıtlardan dolayı gözlemlenen arıza verisi sayısı oldukça azdır. Bu nedenle olasılık kağıtları güvenilirlik analizinde yoğun olarak kullanılmaktadır. Olasılık kağıdının amacı, uygun bir arıza-zaman dağılımını tanımlamak ve bu dağılımın parametre tahminlerini elde etmektir. Test edilen ürünlerin maliyetleri düşünüldüğünde, güvenilirlik analizinde büyük örneklemleri gerektirmeyen ve güvenilir sonuçlar veren olasılık kağıdı oldukça önemlidir. Arıza verilerinin az olması nedeniyle, olasılık kağıdı kullanımı çoğu zaman güvenilirlik mühendislerinin sahip olduğu tek araçtır [25]. Ayrıca, bir sistemin güvenilirliği hakkında sonuç çıkarımı yapmak istenildiğinde, bu sisteme ilişkin elemanların yaşam zamanlarını gözlemlemek her zaman mümkün olmayabilir. Güvenilirlik analizinde yaşam süreleri tam olarak bilinmeyen gözlemler sansürlü gözlemler olarak adlandırılmaktadır. Sansürlenmiş verilerin varlığı, yaşam analizini diğer istatistiksel modellerden ayıran en belirgin özelliktir. Yaşam modellerinde sansürlenmiş veri durumunda parametrik olmayan yaklaşımlar çoğunluktadır. Ancak parametrik yöntemler daha güvenilir sonuçlar vermektedir. Parametrik yaşam modellerinde tam ve sansürlü örnekleme dayalı olarak tahmin yapmak için genel olarak En Cok Olabilirlik (EÇO) tahmin yöntemi kullanılmaktadır. Ancak EÇO tahmin edicisinin etkinliği örneklem hacminin yeteri kadar büyük olmaması durumunda azalmaktadır. Güvenilirlik çalışmalarında olduğu gibi küçük ve sansürlü örneklem hacimlerinde klasik tahmin edicilerin etkinliği azalmaktadır. Ayrıca yaşam modellerinde parametre tahmini yapılırken bazı önemli durumların 
göz önünde bulundurulması gerekir. Arıza verilerinin dağılımı hatalı belirlenebilir ya da veri setinde aykırı değerler bulunabilir. Bu durum EÇO veya diğer klasik tahmin edicilerin etkinliğini azaltan bir faktördür. Sağlam tahmin ediciler varsayımsal bozulmaların üstesinden gelmek için geliştirilmiş tahmin edicilerdir. Modelin varsayımları sağlanamadığında veya aykırı değerler nedeniyle klasik tahmin edicilerin etkinliğinin azaldığı durumlarda tercih edilmektedir.

Yaşam modellerinde alandan gelen veri genellikle ilerleyen sansürlenmiş veri şeklindedir. Dolayısıyla ilerleyen sansürlü örneklemlere dayalı parametre tahmini oldukça önemlidir. Yukarıdaki problemler göz önünde bulundurulduğunda parametre tahmini için sağlam istatistiksel yöntemlerin tercih edilmesi daha doğru olacaktır. Bu çalışmada ilerleyen sansürlenmiş örneklem durumunda parametre tahmini için EKK tahmin edicisine alternatif olacak sağlam tahmin ediciler ele alınmıștır. Weibull dağılımının şekil parametresi basit doğrusal regresyon modeli kullanılarak tahmin edilmiştir. Tahmin yöntemi olarak EKK ve sağlam (robust) tahmin yöntemi olan M (Huber, Tukey ve Hampel) tahmin edicileri ele alınmıştır. Weibull dağılımını şekil parametresinin tahmini için, bu tahmin yöntemlerinin etkinlikleri sansürleme oranına ve veri setinin aykırı değer içerip içermeme durumuna göre simülasyon çalışması ile karşılaştırılmıştır.

Çalışmanın 2'inci bölümünde Weibull dağılımı doğrusal regresyon analizi yardımıyla parametre tahmini açıklanmıştır. Klasik olarak kullanılan EKK tahmin edicisi ve ona alternatif olarak önerilen $M$ tahmin edicileri açıklanmıştır. 3'üncü bölümde Weibull dağılımının şekil parametresinin tahmininde ele alınan bu tahmin ediciler farklı koşullar altında Monte Carlo simülasyonu ile karşılaştırılmışlardır. Tahmin edicilerin karşılaştırılmasında yanlılık ve hata kareler ortalaması ölçütlerinden yararlanılmıştır. Elde edilen sonuçlar Bölüm 4'te verilmiştir. $\mathrm{Bu}$ çalışmada ilerleyen sansürlü örnekleme dayalı olarak Weibull dağılımının şekil parametresinin aykırı değer durumuna göre en etkin tahmin edicisi belirlenmeye çalışılmıştır.

\section{Materyal ve Metot}

Güvenilirlik analizi için en yaygın kullanım alanına sahip dağılım, Weibull olasılık dağılımıdır. Bu dağılım, bileşen ömrünü dalgalı tehlike oranı fonksiyonlarıyla modellemek ve çeşitli mühendislik uygulamalarını temsil etmek için uygundur.

\subsection{Weibull dağılımı}

Weibull dağılımı içerdiği parametre sayısına göre iki parametreli veya üç parametreli Weibull dağılımı olarak adlandırılmaktadır. Weibull dağılımı sadece şekil ve ölçek parametresini içeriyorsa iki parametreli Weibull dağılımı olarak adlandırılır. Eğer arıza verileri için bir eşik (threshold) değeri söz konusu ise, konum, ölçek ve şekil parametresi içeren üç parametreli Weibull dağılımı kullanılmalıdır. Weibull dağılımı şekil parametresinin aldığı farklı değerlere göre oldukça farklı veri yapılarını modellemede başarılı bir dağılımdır. Şekil parametre değeri 1 olduğunda üstel dağılım, 2 olduğunda Raiyleigh dağılımı, 3.4 olduğunda ise normal dağılıma dönüşmektedir. $\mathrm{Bu}$ nedenle arıza verilerinin modellenmesi aşamasında şekil parametresinin doğru tahmini büyük öneme sahiptir. Şekil parametresinin tahminine bağlı olarak yapılacak çıkarsamaların ve olasılık hesaplarının tamamı buna bağlıdır. İki parametreli Weibull dağılımının oyf Eșitlik (1)'de verilmiștir.

$$
f(t ; \alpha, \mu)=\frac{\alpha(t)^{\alpha-1}}{\sigma^{\alpha}} e^{-\left(\frac{t}{\sigma}\right)^{\alpha}} \quad t \geq \mu \geq 0
$$

Weibull dağılımının birikimli dağılım fonksiyonu ise,

$$
F(t ; \alpha, \mu)=1-e^{-\left(\frac{t}{\sigma}\right)^{\alpha}} \quad t \geq \mu \geq 0
$$

biçimindedir [2]. Çeşitli şekil parametre değerleri için standart Weibull dağılımının oyf grafiği Şekil-1 de verilmiştir.

Weibull Distribution PDF (scale=1)

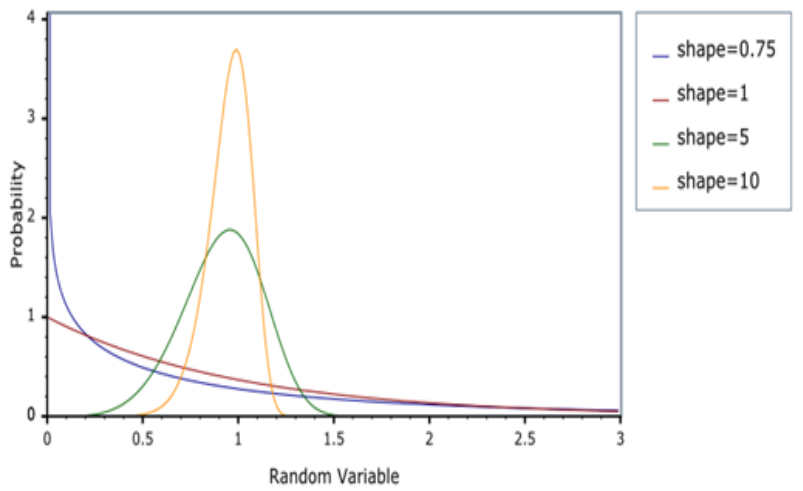

Şekil 1. Weibull dağılımının oyf

\subsection{Doğrusal regresyon analizi ile parametre tahmini}

Literatürde Weibull dağılımının parametre tahminine ilişkin birçok çalışma mevcuttur. Ancak ilerleyen sansürlü küçük örneklem durumunda veri setinin aykırı değer içermesi durumuna ilişkin az sayıda çalışma söz konusudur. Bu çalışma kapsamında ilerleyen sansürlü örnekleme dayalı olarak parametre tahmini için regresyon analizinden yararlanılmıştır.

$X_{1}, X_{2}, \ldots, X_{n}$ Eşitlik 1'de verilen Weibull dağılımından $n$ birimlik rassal bir örneklem olsun. $X_{(1)}<X_{(2)}<$ $\ldots<X_{(n)}$ Weibull dağılımından sıra istatistiklerini göstersin. Eşitlik 2'de verilen Weibull dağılımının birikimli dağılım fonksiyonunun iki kez logaritması alınarak doğrusallaştırıldığında. 


$$
\begin{aligned}
\ln \left\{-\ln \left[1-F\left(x_{(i)}\right)\right]\right\} & =-\beta \ln \alpha+\beta \ln x_{(i)}, \\
i & =1, \ldots, n
\end{aligned}
$$

elde edilir. Burada, $\mathrm{y}=\ln \left\{-\ln \left[1-F\left(x_{(i)}\right)\right]\right\}$ olarak alınabilir. Bu durumda, Eşitlik 3'te verilen ifade doğrusal regresyon denklemi biçiminde yazılabilir [3].

$$
y=\beta \ln \alpha+\beta \ln x_{(i)}, \quad i=1, \ldots, n
$$

Eşitlik 4'te verilen doğrusal regresyon modeli kullanılarak Weibull dağılımının şekil ve ölçek parametreleri tahmin edilebilir. Burada önemli olan bir nokta $F(x)^{\prime}$ in tahminidir. $F(x)$ nonparametrik tahmini için birçok yöntem vardır. Bu çalışmada ilerleyen sansürlü örneklem durumu ele alındığından Herd-Johnson tahmin edicisi kullanılmıştır. HerdJohnson tahmin edicisi sansürlü veriler için başarısızlık olasılıklarını tahmin etmede yaygın olarak kullanılmaktadır. Herd Johnson tahmin edicisi Eşitlik 5'te verilmiştir.

$$
\begin{aligned}
& \text { Herd - Johnson Estimator } \\
& =\left\{\begin{array}{l}
\hat{R}_{f,(j)}=\left(\frac{n+1-I_{j}}{n+2-I_{j}}\right) x \widehat{R}_{f,(j-1)} \\
\hat{F}_{f,(j)}=1-\hat{R}_{f,(j)}
\end{array}\right.
\end{aligned}
$$

$I_{j}$; örneklemdeki $j^{\text {th }}$ arızanın sayısını belirtmektedir. Hem başarısızlık hem de sansür oluşumu olay olarak kabul edilir. $\hat{R}_{f,(j)} ; \hat{F}_{f,(j)}$ 'nin tümleyenidir ve $\hat{R}_{f,(0)}=1$.

\subsection{En küçük kareler yöntemi}

En Küçük Kareler (Ordinary Least Squares-EKK) yöntemi, modelden elde edilen tahmin edilen değerleri ile gözlemlenen değerler arasındaki sapmaların karelerinin en aza indirgenmesine dayanmaktadır. Bir başka ifadeyle artık kareler toplamının minimizasyonuna dayalı olarak parametre tahminini gerçekleştirmektedir. Eşitlik 4 'te verilen basit doğrusal regresyon modeli için EKK tahmin edicileri,

$$
S\left(\beta_{0}, \beta_{1}\right)=\sum_{i=1}^{n}\left(y_{i}-\beta_{0}-\beta_{1} x_{i}\right)^{2}
$$

şeklinde ifade edilen amaç fonksiyonu yardımıyla elde edilir. Eşitlik 6'daki amaç fonksiyonu kullanılarak, Weibull dağılımının şekil parametresinin EKK tahmin edicisi aşağıdaki gibi elde edilir [4].

$$
\hat{\alpha}_{O L S}=\frac{\sum_{i=1}^{n}\left(x_{i}-\bar{x}\right)\left(y_{i}-\bar{y}\right)}{\sum_{i=1}^{n}\left(x_{i}-\bar{x}\right)^{2}}
$$

\subsection{M regresyon yöntemi}

Sağlam regresyon yöntemlerinden biri $\mathrm{M}$ tahmin yöntemidir. $M$ harfi, maksimum olabilirlik tipi bir tahmin edici olduğunu göstermektedir. M regresyonda regresyon katsayıları, aşağıdaki amaç fonksiyonunun en aza indirilmesiyle elde edilir.

$$
\begin{gathered}
\min \sum_{i=1}^{n} \rho\left(u_{i}\right)=\min _{\beta} \sum_{i=1}^{n} \rho\left(\frac{e_{i}}{\sigma}\right) \\
=\frac{\min }{\beta} \sum_{i=1}^{n} \rho\left(\frac{y_{i}-\sum_{j=0}^{k} x_{i j} \beta_{i}}{\sigma}\right)
\end{gathered}
$$

Burada, $\hat{\sigma}=\frac{M A D}{0.645}=\frac{\text { median } \mid e_{i}-\text { median }\left(e_{i}\right) \mid}{0.645}$ ve $\rho$ sifir noktasında sabit bir minimumu olan türevlenebilir ve simetrik bir fonksiyondur. Amaç fonksiyonu ve ağırlık değerleri için çeşitli fonksiyonlar önerilmiştir. En popüler olanlardan bazıları Huber, Tukey ve Hampel'dir. Ancak, hangi metodun seçileceği konusunda standart bir kriter yoktur ve bu nedenle seçimi araştırmacıya bırakılmıştır [26, 27].

Huber M tahmin edisici içim ağırlı fonksiyonu ve $k$ değeri,

$$
w=\left\{\begin{array}{ll}
1, & |r| \leq k \\
\frac{k}{r}, & |r|>k
\end{array} \quad k=1.345\right.
$$

Tukey Bi-Square tahmin edicisi için ağırlık fonksiyonu ve $k$ değeri

$$
w=\left\{\begin{array}{c}
\left(1-\left(\frac{r}{k}\right)^{2}\right)^{2}, \quad|r| \leq k \\
0, \quad|r|>k \\
k=4.685
\end{array}\right.
$$

ve Hampel M tahmin edicisi için ağırlık fonksiyonu,

$$
w=\left\{\begin{array}{lc}
1 & 0<|r| \leq a \\
\frac{a}{r} \operatorname{sgn}(r) & a<|r| \leq b \\
\frac{a}{r}\left[\frac{c-|r|}{c-b}\right] \operatorname{sgn}(r) & b<|r| \leq c \\
0 & c<|r|
\end{array}\right.
$$

şeklindedir. Burada $a=1.7, b=3.4$ ve $c=8.5^{\prime}$ tir. Mtahmin edicileri iteratif olarak elde edilebilen tahmin edicilerdir. $\mathrm{M}$ tahmin edicilerin hesaplanmasında genel olarak İteratif Yeniden Ağırlıklandırılmış En Küçük Kareler yöntemi kullanılmaktadır [5]. İteratif yeniden ağırlıklandırılmış EKK yönteminin adımları kısaca așağıdaki gibidir.

a) İlk olarak $\theta$ parametresinin tahmin değeri $\hat{\theta}$ elde edilir.

b) Bu tahmin değeri kullanılarak artıklar hesaplanır.

c) Artıklara ilişkin standart hata değerinin hesaplanmasında sağlam bir ölçü olan MAD kullanılır.

d) Ağırlık fonksiyonları aracılığıyla gözlemlere verilecek ağırlıklar hesaplanır. 
e) Ağırlıklandırılmış EKK yöntemi yardımıyla $\hat{\theta}$ nın güncel değeri hesaplanır.

f) İki tahmin değeri arasındaki fark 0.0001 olana kadar iterasyona devam edilir.

\section{Simülasyon Çalışması}

Simülasyon çalışmasında, ilerleyen sansürlü rassal örneklemler Weibull dağılımının çeşitli şekil parametreleri için standart Weibull dağllımı kullanılarak üretilmiştir. Güvenilirlik analizinde küçük veri setleri ile çalışıldığından örneklem büyüklüğü için, $n=20,30,50$ ve 100 ; şekil parametresinin gerçek değerleri için $c=1,2$ ve 3. 4; sansürleme seviyeleri (censored level-CL) için ise CL= $0.2,0.4,0.6,0.8$ değerleri ele alınmıștır. EKK ve M tahmin edicilerinin Weibull şekil parametresini tahmin etmedeki performansları küçük, ilerleyen sansürlü veri kümelerinde aykırı değer içeren ve içermeyen durumlar göz önünde bulundurularak karşılaştırılmıştır. Genelliği bozmamak için simülasyonlarda $\sigma, 1$ olarak alınmıştır. Simülasyonlar, örneklem hacminin, şekil parametresinin, sansürleme

Tablo 1. $\alpha=1$ olan Weibull dağılımının şekil parametresinin tahmin edicilerine ilişkin HKO ve yan değerleri

\begin{tabular}{|c|c|c|c|c|c|c|c|c|}
\hline \multicolumn{9}{|c|}{ Aykırı Değersiz Veri } \\
\hline Sansür Oranı & & & & $\% 20$ & sürlü Ver & & & \\
\hline \multirow{2}{*}{ Tahmin Ediciler } & \multicolumn{2}{|c|}{$n=20$} & \multicolumn{2}{|c|}{$\mathrm{n}=30$} & \multicolumn{2}{|c|}{$n=50$} & \multicolumn{2}{|c|}{$\mathrm{n}=100$} \\
\hline & Yan & HKO & Yan & HKO & Yan & $\mathrm{HKO}$ & Yan & HKO \\
\hline EKK & -0.0904 & 0.0594 & -0.0714 & 0.0438 & -0.0546 & 0.0267 & -0.0273 & 0.0147 \\
\hline HUBER & -0.0813 & 0.0542 & -0.0521 & 0.0375 & -0.0276 & 0.0209 & -0.0103 & 0.0100 \\
\hline TUKEY & -0.0789 & 0.0542 & -0.0483 & 0.0382 & -0.0274 & 0.0213 & -0.0102 & 0.0106 \\
\hline \multirow[t]{2}{*}{ HAMPEL } & -0.0853 & 0.0542 & -0.0546 & 0.0388 & -0.0291 & 0.0215 & -0.0106 & 0.0107 \\
\hline & \multicolumn{8}{|c|}{ \%40 Sansürlü Veri } \\
\hline EKK & -0.0701 & 0.0767 & -0.0532 & 0.0559 & -0.0340 & 0.0350 & -0.0158 & 0.0187 \\
\hline HUBER & -0.0613 & 0.0648 & -0.0373 & 0.0457 & -0.0172 & 0.0268 & -0.0097 & 0.0144 \\
\hline TUKEY & -0.0609 & 0.0650 & -0.0370 & 0.0487 & -0.0151 & 0.0277 & -0.0095 & 0.0147 \\
\hline \multirow[t]{2}{*}{ HAMPEL } & -0.0628 & 0.0657 & -0.0390 & 0.0494 & -0.0186 & 0.0279 & -0.0098 & 0.0154 \\
\hline & \multicolumn{8}{|c|}{ \%60 Sansürlü Veri } \\
\hline EKK & -0.0530 & 0.1168 & -0.0413 & 0.0821 & -0.0266 & 0.0478 & 0.0218 & 0.0269 \\
\hline HUBER & -0.0406 & 0.0948 & -0.0321 & 0.0710 & -0.0158 & 0.0344 & -0.0106 & 0.0175 \\
\hline TUKEY & -0.0394 & 0.0947 & -0.0318 & 0.0713 & -0.0139 & 0.0347 & -0.0102 & 0.0179 \\
\hline \multirow[t]{2}{*}{ HAMPEL } & -0.0410 & 0.0961 & -0.0324 & 0.0715 & -0.0173 & 0.0348 & -0.0117 & 0.0182 \\
\hline & \multicolumn{8}{|c|}{ \%80 Sansürlü Veri } \\
\hline EKK & 0.1161 & 0.4436 & 0.0587 & 0.1762 & 0.0492 & 0.0954 & 0.0380 & 0.0653 \\
\hline HUBER & 0.0919 & 0.3445 & 0.0452 & 0.1573 & 0.0344 & 0.0894 & 0.0191 & 0.0545 \\
\hline TUKEY & 0.0912 & 0.3447 & 0.0439 & 0.1572 & 0.0343 & 0.0895 & 0.0173 & 0.0565 \\
\hline HAMPEL & 0.0922 & 0.3444 & 0.0457 & 0.1575 & 0.0347 & 0.0894 & 0.0193 & 0.0598 \\
\hline \multicolumn{9}{|c|}{ Aykırı Değerli Veri } \\
\hline Sansür Oranı & \multicolumn{8}{|c|}{ \%20 Sansürlü Veri } \\
\hline \multirow{2}{*}{ Tahmin Ediciler } & \multicolumn{2}{|c|}{$\mathrm{n}=20$} & \multicolumn{2}{|c|}{$\mathrm{n}=30$} & \multicolumn{2}{|c|}{$\mathrm{n}=50$} & \multicolumn{2}{|c|}{$n=100$} \\
\hline & Yan & HKO & Yan & HKO & Yan & HKO & Yan & HKO \\
\hline EKK & -0.4395 & 0.2132 & -0.3866 & 0.1642 & -0.3185 & 0.1107 & -0.2193 & 0.0540 \\
\hline HUBER & -0.2861 & 0.1211 & -0.1587 & 0.0555 & -0.0788 & 0.0249 & -0.0226 & 0.0111 \\
\hline TUKEY & -0.2831 & 0.1221 & -0.1559 & 0.0562 & -0.0769 & 0.0254 & -0.0219 & 0.0119 \\
\hline HAMPEL & -0.2873 & 0.1237 & -0.1630 & 0.0598 & -0.0807 & 0.0259 & -0.0235 & 0.0118 \\
\hline & \multicolumn{8}{|c|}{ \%40 Sansürlü Veri } \\
\hline EKK & -0.4469 & 0.2280 & -0.4010 & 0.1789 & -0.3331 & 0.1227 & -0.2289 & 0.0602 \\
\hline HUBER & -0.2982 & 0.1379 & -0.2028 & 0.0777 & -0.0873 & 0.0327 & -0.0310 & 0.0160 \\
\hline TUKEY & -0.2985 & 0.1388 & -0.2018 & 0.0785 & -0.0851 & 0.0329 & 0.0295 & 0.0181 \\
\hline \multirow[t]{2}{*}{ HAMPEL } & -0.2996 & 0.1393 & -0.2053 & 0.0796 & -0.0884 & 0.0379 & 0.0316 & 0.0174 \\
\hline & \multicolumn{8}{|c|}{ \%60 Sansürlü Veri } \\
\hline EKK & -0.4540 & 0.2440 & -0.4370 & 0.1840 & -0.3572 & 0.1440 & -0.2549 & 0.0753 \\
\hline HUBER & -0.3044 & 0.1493 & -0.2229 & 0.0873 & -0.0930 & 0.0537 & 0.0409 & 0.0216 \\
\hline TUKEY & -0.3024 & 0.1523 & -0.2208 & 0.0882 & -0.0894 & 0.0568 & 0.0398 & 0.0232 \\
\hline HAMPEL & -0.3049 & 0.1532 & -0.2244 & 0.0895 & -0.0953 & 0.0581 & 0.0416 & 0.0231 \\
\hline & & & & $\% 80$ & sürlü Ver & & & \\
\hline EKK & -0.4935 & 0.5065 & -0.4396 & 0.4353 & -0.3780 & 0.1777 & -0.3098 & 0.1127 \\
\hline HUBER & -0.3409 & 0.2406 & -0.3220 & 0.2241 & -0.2655 & 0.1074 & -0.0779 & 0.0447 \\
\hline TUKEY & -0.3403 & 0.2406 & -0.3209 & 0.2245 & -0.2590 & 0.1073 & -0.0649 & 0.0467 \\
\hline HAMPEL & -0.3406 & 0.2407 & -0.3234 & 0.2269 & -0.2763 & 0.1077 & -0.0786 & 0.0476 \\
\hline
\end{tabular}


oranının ve veri setinin aykırı değer içerme durumunun tüm kombinasyonları için, 100000/n tekrarlı olarak gerçekleştirilmiştir. Tüm hesaplamalar MATLAB programı kullanılarak yapılmıștır. Tahmin edicilerin performasını değerlendirmek için yan ve hata kareler ortalaması ölçütü kullanılmıştır.

$$
\begin{gathered}
\operatorname{Yan}(\hat{\alpha})=E(\hat{\alpha})-\alpha \\
H K O(\hat{c})=\frac{1}{(100000 / n)} \sum(\hat{\alpha}-\alpha)^{2}
\end{gathered}
$$

Elde edilen sonuçlar Tablo 1-3 de verilmiștir.
Tablo 1-3 HKO açısından incelendiğinde; EKK tahmin edicisinin $\mathrm{M}$ tahmin edicilerine göre etkin olmadığ görülmektedir. Genellikle M tahmin edicilerinin HKO değeri EKK tahmin edicisinden küçüktür. Şekil parametresi $\mathrm{c}=1$ olduğu durumlarda Weibull dağılımı negatif çarpık olduğundan, en etkin sonucu veren $M$ tahmin edicisi Huber $\mathrm{M}$ tahmin edicisidir. Veri setinde aykırı değer bulunmadığı durumda tahmin edicilerin HKO değerleri daha küçüktür. Ayrıca sansür oranı arttıkça yanlılık miktarı belirli bir seviyeye kadar azalsa da tahmin edicilerin HKO değerleri artmaktadır. n'in tüm değerlerinde ve tüm sansür oranlarında, veri setinin aykırı değer içerip

\begin{tabular}{|c|c|c|c|c|c|c|c|c|}
\hline \multicolumn{9}{|c|}{ Aykırı Değersiz Veri } \\
\hline Sansür Oranı & \multicolumn{8}{|c|}{ \%20 Sansürlü Veri } \\
\hline \multirow{2}{*}{ Tahmin Ediciler } & \multicolumn{2}{|c|}{$n=20$} & \multicolumn{2}{|c|}{$\mathrm{n}=30$} & \multicolumn{2}{|c|}{$\mathrm{n}=50$} & \multicolumn{2}{|c|}{$\mathrm{n}=100$} \\
\hline & Yan & HKO & Yan & HKO & Yan & HKO & Yan & HKO \\
\hline EKK & -0.1691 & 0.2499 & -0.1485 & 0.1624 & -0.1041 & 0.1053 & -0.0385 & 0.0365 \\
\hline HUBER & -0.1515 & 0.2457 & -0.1187 & 0.1546 & -0.0824 & 0.0922 & -0.0128 & 0.0195 \\
\hline TUKEY & -0.1503 & 0.2464 & -0.1179 & 0.1554 & -0.0810 & 0.0932 & 0.0112 & 0.0211 \\
\hline HAMPEL & -0.1546 & 0.2468 & -0.1196 & 0.1562 & -0.0838 & 0.0942 & 0.0147 & 0.0223 \\
\hline & \multicolumn{8}{|c|}{ \%40 Sansürlü Veri } \\
\hline EKK & -0.1428 & 0.2904 & -0.1080 & 0.2057 & -0.0701 & 0.1341 & 0.0083 & 0.0486 \\
\hline HUBER & -0.1335 & 0.2838 & -0.0811 & 0.1915 & -0.0521 & 0.1125 & 0.0045 & 0.0239 \\
\hline TUKEY & -0.1314 & 0.2849 & -0.0805 & 0.1905 & -0.0512 & 0.1143 & 0.0039 & 0.0245 \\
\hline \multirow[t]{2}{*}{ HAMPEL } & -0.1349 & 0.2855 & -0.0840 & 0.1925 & -0.0572 & 0.1173 & 0.0052 & 0.0277 \\
\hline & \multicolumn{8}{|c|}{ \%60 Sansürlü Veri } \\
\hline EKK & -0.0822 & 0.4418 & -0.0396 & 0.2952 & -0.0147 & 0.1743 & 0.0074 & 0.1027 \\
\hline HUBER & -0.0747 & 0.4180 & -0.0343 & 0.2790 & -0.0113 & 0.1417 & 0.0041 & 0.0734 \\
\hline TUKEY & -0.0739 & 0.4187 & -0.0340 & 0.2795 & -0.0108 & 0.1435 & 0.0037 & 0.0738 \\
\hline \multirow[t]{2}{*}{ HAMPEL } & -0.0767 & 0.4195 & -0.0345 & 0.2812 & -0.0115 & 0.1445 & 0.0043 & 0.0742 \\
\hline & \multicolumn{8}{|c|}{ \%80 Sansürlü Veri } \\
\hline EKK & 0.0243 & 1.7585 & 0.1120 & 0.6686 & 0.1075 & 0.3625 & 0.0970 & 0.2199 \\
\hline HUBER & 0.0208 & 1.7023 & 0.0990 & 0.5329 & 0.0865 & 0.2825 & 0.0200 & 0.1695 \\
\hline TUKEY & 0.0203 & 1.7079 & 0.0911 & 0.5383 & 0.0864 & 0.2831 & 0.0193 & 0.1741 \\
\hline HAMPEL & 0.0212 & 1.7159 & 0.1008 & 0.5403 & 0.0870 & 0.2894 & 0.0204 & 0.1788 \\
\hline \multicolumn{9}{|c|}{ Aykırı Değerli Veri } \\
\hline Sansür Oranı & \multicolumn{8}{|c|}{ \%20 Sansürlü Veri } \\
\hline \multirow{2}{*}{ Tahmin Ediciler } & \multicolumn{2}{|c|}{$n=20$} & \multicolumn{2}{|c|}{$\mathrm{n}=30$} & \multicolumn{2}{|c|}{$\mathrm{n}=50$} & \multicolumn{2}{|c|}{$\mathrm{n}=100$} \\
\hline & Yan & HKO & Yan & HKO & Yan & HKO & Yan & HKO \\
\hline EKK & -0.6487 & 0.9837 & -0.5771 & 0.7651 & -0.4634 & 0.4389 & -0.3281 & 0.2110 \\
\hline HUBER & -0.5217 & 0.3732 & -0.3166 & 0.2155 & -0.1542 & 0.0978 & -0.0540 & 0.0403 \\
\hline TUKEY & -0.5209 & 0.3898 & -0.3098 & 0.2318 & -0.1402 & 0.0986 & 0.0522 & 0.0453 \\
\hline HAMPEL & -0.5227 & 0.3966 & -0.3200 & 0.2460 & -0.1615 & 0.0992 & 0.0602 & 0.0441 \\
\hline & \multicolumn{8}{|c|}{ \%40 Sansürlü Veri } \\
\hline EKK & -0.6589 & 1.9052 & -0.5828 & 1.4719 & -0.4867 & 0.8494 & -0.3546 & 0.4242 \\
\hline HUBER & -0.5248 & 0.7386 & -0.3229 & 0.4319 & -0.1770 & 0.1288 & -0.0774 & 0.0749 \\
\hline TUKEY & -0.5225 & 0.7446 & -0.3218 & 0.4575 & 0.1716 & 0.1320 & 0.0738 & 0.0765 \\
\hline \multirow[t]{2}{*}{ HAMPEL } & -0.5265 & 0.7689 & -0.3285 & 0.4629 & -0.1841 & 0.1452 & 0.0849 & 0.0846 \\
\hline & \multicolumn{8}{|c|}{ \%60 Sansürlü Veri } \\
\hline EKK & -0.6756 & 2.1993 & -0.6148 & 1.7964 & -0.5038 & 1.1158 & -0.3821 & 0.7297 \\
\hline HUBER & -0.5422 & 0.9835 & -0.3472 & 0.6818 & -0.2073 & 0.3841 & 0.0973 & 0.1077 \\
\hline TUKEY & -0.5419 & 1.0022 & -0.3463 & 0.6952 & -0.2107 & 0.3892 & 0.0959 & 0.1108 \\
\hline HAMPEL & -0.5453 & 1.0200 & -0.3480 & 0.7072 & -0.2119 & 0.3918 & 0.0991 & 0.1145 \\
\hline & & & & $\% 80 \mathrm{~S}$ & ürlü Veri & & & \\
\hline EKK & -0.8234 & 4.6470 & -0.7971 & 3.4962 & -0.7546 & 2.2720 & -0.6061 & 1.4367 \\
\hline HUBER & -0.6982 & 1.6352 & -0.4036 & 1.1298 & -0.2730 & 0.7039 & -0.1384 & 0.3661 \\
\hline TUKEY & -0.6974 & 1.6552 & -0.4031 & 1.1330 & -0.2704 & 0.7094 & 0.1257 & 0.3769 \\
\hline HAMPEL & -0.7018 & 1.6770 & -0.4129 & 1.1400 & -0.2751 & 0.7185 & -0.1408 & 0.3898 \\
\hline
\end{tabular}

Tablo 2. $\alpha=2$ olan Weibull dağılımının şekil parametresinin tahmin edicilerine ilișkin HKO ve yan Değerleri 
Tablo 3. $\alpha=3.4$ olan Weibull dağılımının șekil parametresinin tahmin edicilerine ilișkin HKO ve yan değerleri

\begin{tabular}{|c|c|c|c|c|c|c|c|c|}
\hline \multicolumn{9}{|c|}{ Aykırı Değersiz Veri } \\
\hline Sansür Oranı & & & & $\% 20 \mathrm{~S}$ & ürlü Veri & & & \\
\hline \multirow{2}{*}{ Tahmin Ediciler } & \multicolumn{2}{|c|}{$n=20$} & \multicolumn{2}{|c|}{$\mathrm{n}=30$} & \multicolumn{2}{|c|}{$\mathrm{n}=50$} & \multicolumn{2}{|c|}{$n=100$} \\
\hline & Yan & HKO & Yan & HKO & Yan & HKO & Yan & HKO \\
\hline EKK & -0.3267 & 0.7071 & -0.2738 & 0.4856 & -0.1962 & 0.3006 & -0.1113 & 0.1246 \\
\hline HUBER & -0.3130 & 0.6902 & -0.2613 & 0.4770 & -0.1879 & 0.2931 & -0.1025 & 0.1151 \\
\hline TUKEY & -0.3126 & 0.6912 & -0.2615 & 0.4776 & -0.1874 & 0.2933 & 0.1020 & 0.1163 \\
\hline \multirow[t]{2}{*}{ HAMPEL } & -0.3134 & 0.6915 & -0.2620 & 0.4793 & -0.1889 & 0.2948 & -0.1036 & 0.1168 \\
\hline & \multicolumn{8}{|c|}{ \%40 Sansürlü Veri } \\
\hline EKK & -0.2839 & 0.8438 & -0.2465 & 0.6012 & -0.1513 & 0.4048 & 0.0520 & 0.1849 \\
\hline HUBER & -0.2781 & 0.8346 & -0.2382 & 0.5913 & -0.1458 & 0.3929 & 0.0427 & 0.1746 \\
\hline TUKEY & -0.2779 & 0.8355 & -0.2367 & 0.5936 & 0.1447 & 0.3935 & 0.0415 & 0.1754 \\
\hline \multirow[t]{2}{*}{ HAMPEL } & -0.2786 & 0.8361 & -0.2386 & 0.5941 & -0.1452 & 0.3946 & 0.0437 & 0.1768 \\
\hline & \multicolumn{8}{|c|}{ \%60 Sansürlü Veri } \\
\hline EKK & 0.1887 & 1.3062 & -0.1513 & 0.7936 & -0.0639 & 0.4844 & 0.0442 & 0.2654 \\
\hline HUBER & -0.1782 & 1.0491 & -0.1445 & 0.7827 & 0.0580 & 0.4639 & 0.0347 & 0.2406 \\
\hline TUKEY & -0.1770 & 1.0529 & -0.1440 & 0.7833 & 0.0578 & 0.4649 & 0.0322 & 0.2417 \\
\hline \multirow[t]{2}{*}{ HAMPEL } & -0.1796 & 1.0614 & -0.1453 & 0.7839 & 0.0593 & 0.4653 & 0.0352 & 0.2425 \\
\hline & \multicolumn{8}{|c|}{ \%80 Sansürlü Veri } \\
\hline EKK & 0.2298 & 4.6792 & 0.1681 & 1.9189 & 0.0782 & 0.9366 & 0.0689 & 0.5318 \\
\hline HUBER & 0.2233 & 4.3500 & 0.1590 & 1.7353 & 0.0691 & 0.9224 & 0.0529 & 0.5230 \\
\hline TUKEY & 0.2226 & 4.4903 & 0.1576 & 1.7532 & 0.0688 & 0.9231 & 0.0524 & 0.5238 \\
\hline HAMPEL & 0.2238 & 4.4920 & 0.1596 & 1.7776 & 0.0701 & 0.9239 & 0.0533 & 0.5241 \\
\hline \multicolumn{9}{|c|}{ Aykırı Değerli Veri } \\
\hline Sansür Oranı & \multicolumn{8}{|c|}{ \%20 Sansürlü Veri } \\
\hline \multirow{2}{*}{ Tahmin Ediciler } & \multicolumn{2}{|c|}{$\mathrm{n}=20$} & \multicolumn{2}{|c|}{$\mathrm{n}=30$} & \multicolumn{2}{|c|}{$\mathrm{n}=50$} & \multicolumn{2}{|c|}{$\mathrm{n}=100$} \\
\hline & Yan & $\mathrm{HKO}$ & Yan & HKO & Yan & HKO & Yan & HKO \\
\hline EKK & -2.0506 & 4.5167 & -1.3186 & 2.3903 & -1.0775 & 1.2674 & -0.7532 & 0.8636 \\
\hline HUBER & -0.9862 & 1.5943 & -0.4154 & 0.6298 & -0.2753 & 0.3529 & -0.2095 & 0.1799 \\
\hline TUKEY & -0.9846 & 1.6176 & -0.4132 & 0.6452 & -0.2550 & 0.3652 & 0.2059 & 0.1824 \\
\hline \multirow[t]{2}{*}{ HAMPEL } & -0.9928 & 1.6316 & -0.4346 & 0.6563 & -0.2912 & 0.3728 & -0.2170 & 0.1862 \\
\hline & \multicolumn{8}{|c|}{ \%40 Sansürlü Veri } \\
\hline EKK & -2.1537 & 4.8671 & -1.3921 & 2.8453 & -1.1449 & 1.4536 & -0.7991 & 0.9721 \\
\hline HUBER & -1.0037 & 1.8317 & -0.4727 & 0.9335 & -0.3054 & 0.3749 & -0.2361 & 0.2827 \\
\hline TUKEY & -1.0023 & 1.8596 & -0.4632 & 0.9790 & -0.2962 & 0.3863 & 0.2396 & 0.2899 \\
\hline \multirow[t]{2}{*}{ HAMPEL } & -1.0095 & 1.9361 & -0.4840 & 0.9954 & -0.3186 & 0.4136 & 0.2487 & 0.2936 \\
\hline & & & & $\% 60 \mathrm{~S}$ & ürlü Veri & & & \\
\hline EKK & -2.5403 & 7.9668 & -1.4416 & 3.4091 & -1.2853 & 1.8769 & -0.9821 & 1.1927 \\
\hline HUBER & -1.2553 & 2.3883 & -0.6258 & 1.0612 & -0.3469 & 0.4616 & -0.2519 & 0.3214 \\
\hline TUKEY & -1.2554 & 2.4209 & -0.5911 & 1.0971 & -0.3279 & 0.4641 & 0.2478 & 0.3298 \\
\hline HAMPEL & -1.2638 & 2.7438 & -0.7014 & 1.1135 & -0.3646 & 0.4932 & 0.2656 & 0.3400 \\
\hline & & & & $\% 80 \mathrm{~S}$ & ürlü Veri & & & \\
\hline EKK & -2.8844 & 9.2849 & -1.8399 & 4.1926 & -1.6394 & 3.2118 & -1.2631 & 2.1342 \\
\hline HUBER & -1.4340 & 2.6858 & -0.8409 & 1.3975 & -0.5935 & 0.7152 & -0.4226 & 0.4834 \\
\hline TUKEY & -1.4143 & 2.7345 & -0.8241 & 1.4021 & -0.5325 & 0.7477 & 0.4182 & 0.4973 \\
\hline HAMPEL & -1.4384 & 2.9849 & -0.8739 & 1.4947 & -0.6233 & 0.8204 & -0.4298 & 0.5085 \\
\hline
\end{tabular}

içermemesine bağlı olmaksızın Weibull dağılımının şekil parametresini en etkin şekilde tahmin eden tahmin edici $\mathrm{M}$ tahmin edicileri olarak belirlenmiștir. Şekil parametre değer 3.4 olduğunda Weibull dağılımı simetrik hale geldiğinden örneklem hacmi arttıkça EKK tahmin edicisi $\mathrm{M}$ tahmin edicileri ile yaklașık olarak benzer sonuçlar vermektedir. Genel olarak bakıldığında veri setinin çarpık olma durumuna göre farklı ağırlıklar kullanılabilen M tahmin edicilerin HKO değerleri en küçüktür.

Tablo 1-3 yanlılık açısından incelendiğinde; şekil parametresi $\alpha=1$ olduğu durumda, M tahmin edicileri tüm örneklem hacimlerinde ve sansürleme oranlarında en küçük yan değerine sahip tahmin edicilerdir. Aykırı değerlerin varlığı durumunda da yine bu tahmin ediciler en az etkilenen tahmin ediciler olmuştur. Yanlılık miktarı sansür oranından ve aykırı değerlerden en fazla etkilenen tahmin edici ise klasik olarak kullanılan EKK tahmin edicisidir. Şekil parametresi değeri arttığında tahmin edicilerin yanlılık miktarı da artmaktadır. Sansürleme oranı örneklemde gözlemlenen veri sayısını azalttı̆̆ı için yine tahmin edicilerin yanlılık değeri üzerinde negatif etkiye sahiptir. 
Hem HKO hem de yan değerlerine bakıldığında Weibull dağılımının birçok karakteristik özelliğini belirleyen şekil parametresinin tahmininde M tahmin edicilerinin EKK tahmin edicisinden daha etkin sonuçlar verdiği görülmektedir. M tahmin edicilerinin, şekil parametresinin, örneklem hacminin ve sansürleme oranının farklı değerlerine bağlı olarak gösterdiği performanslar farklılık gösterse bile, klasik olarak kullanılan EKK tahmin edicisine göre en etkin sonucu veren tahmin ediciler olduğu belirlenmiştir. M tahmin edicileri içerisindeki sıralama ise Huber, Tukey ve Hampel M tahmin edicileri șeklindedir. Parametre tahmininde yaygın olarak kullanılan EKK tahmin edicilerinin etkinliği ise örnek hacminin artmasına rağmen azalmaktadır. EKK tahmin edicisi Weibull dağılımının şekil parametresinin tahmininde yanlılı̆̆ en yüksek olan ve HKO değeri en büyük olan tahmin edicidir.

\subsection{Gerçek veri uygulaması}

$\mathrm{Bu}$ bölümde, önerilen tahmin edicilerin performansını göstermek için gerçek hayattan bir veri seti üzerinde uygulama gerçekleştirilmiştir. Bu amaçla Tobias ve Trindade (1995) veri seti kullanılmıştır. $\mathrm{Bu}$ veri seti 20 kapasitör için 5 adet sansürlü, 15 adet bozulma süresinden olușmaktadır [28]. Sansürlenmiş veriler için “+” sembolü kullanılmıştır. Bozulma ve sansürleme zamanları Tablo 4'te verilmiștir.

Tablo 4. 20 adet kapasitöre ait yaşam süreleri

\begin{tabular}{ccccc}
62.29 & 75.07 & 104.99 & 184.73 & 185.49 \\
209.76 & 219.22 & 225.13 & $250+$ & $250+$ \\
$250+$ & $250+$ & $250+$ & 999.95 & 1126.22 \\
1398.03 & 1528.17 & 1708.08 & 1741.19 & 1897.15 \\
\hline
\end{tabular}

$\mathrm{Bu}$ veri seti için Herd Johnson tahmin edicisi kullanılarak $F(x)$ değerleri hesaplanmış ve Tablo 5'te verilmiştir.

Tablo 5. Herd-Johnson tahmin edicisine göre $\widehat{F(x)}$ değerleri

\begin{tabular}{lllll}
\hline 0.05 & 0.10 & 0.14 & 0.19 & 0.24 \\
0.29 & 0.33 & 0.38 & & \\
& & & 0.46 & 0.54 \\
0.61 & 0.69 & 0.77 & 0.85 & 0.92 \\
\hline
\end{tabular}

Çalışmanın devamında Tablo 4'te verilen yaşam süreleri ve Tablo 5'te verilen tahmin değerleri kullanılarak EKK ve M tahmin edicilere dayalı şekil parametre değerleri hesaplanmıştır. EKK şekil parametre değeri 960 olarak belirlenmiştir. Huber M tahmin edicisi için 995.2, Tukey için 982.4 ve Hampel için 970.5 olarak hesaplanmıştır.

\section{Tartışma ve Sonuç}

Bu çalışmada güvenilirlik analizinde en çok kullanılan Weibull dağılımının en önemli karakteristik belirleyicisi olan şekil parametresinin tahmini ele alınmıştır. Güvenilirlik analizinde veriler genellikle zaman ve maliyet nedeniyle sansürlü olarak ortaya çıkmaktadır. Sansür oranı parametre tahmini üzerinde olumsuz etkiye neden olur. Başlangıçta belirlenen hedeften daha az sayıda veri ile analiz yapılması, küçük örneklemlerle tutarlı sonuçlar elde edilmesi gibi bir zorunluluğu ortaya çıkarmaktadır. Ayrıca her alanda olduğu gibi güvenilirlik analizinde de veri seti aykırı değer içerebilir. Tüm bu koşullar göz önünde bulundurulduğunda güvenilirlikle ilgili birçok tahmin için etkin ve tutarlı sonuçlar verecek bir tahmin yönteminin olması yapılacak çalıșmaların geçerlilik ve güvenilirliğini arttıracaktır. Bu çalışmada ilerleyen sansürlü veri setinin aykırı değer içerip içermediği durumlarda Weibull dağılımının şekil parametresinin tahmini için EKK tahmin edicisi ve sağlam M tahmin edicileri karşılaştırılmıștır. Weibull dağılımının şekil parametresinin doğrusal regresyon aracılığı ile tahmin edilmesinde EKK tahmin edicisi kullanıldığı takdirde yanlı ve etkin olmayan sonuçlar elde edilmektedir. Çünkü EKK tahmin edicisinin etkinliği, model varsayımlarının sağlanamaması ve veri setinin aykırı değer içermesi durumunda azalmaktadır. Bu durumda parametre tahmini için sağlam yöntemler tercih edilmelidir.

$\mathrm{Bu}$ çalışmada, sağlam tahmin ediciler arasında en yaygın kullanıma sahip $M$ tahmin yöntemi ele alınmıştır. Gerçekleştirilen simülasyon çalışmasının sonuçları incelendiğinde $\mathrm{M}$ tahmin edicilerinin aykırı değersiz ve aykırı değerli veri setleri için Weibull dağılımının şekil parametresini tahmin etmede EKK tahmin edicisinden daha etkin olduğu görülmüștür. Benzer şekilde Zhang vd. tam ve sansürlü örneklem durumunda Huber M tahmin edicisinin etkin sonuçlar verdiğini göstermiştir [19]. Sonuç olarak güvenilirlik analizinde, ilerleyen sansürlü veri setlerinde aykırı değer olup olmaması durumuna bağlı olmaksızın $M$ tahmin edicilerinin tercih edilmesi önerilir.

\section{Teșekkür}

Bu çalışma, Eskişehir Osmangazi Üniversitesi Bilimsel Araştırma Projeleri Komisyonu 2018-1935 kodlu proje kapsamında desteklenmiştir.

\section{Etik Beyanı}

Bu çalışmada, "Yükseköğretim Kurumları Bilimsel Araștırma ve Yayın Etiği Yönergesi" kapsamında uyulması gerekli tüm kurallara uyulduğunu, bahsi geçen yönergenin "Bilimsel Araştırma ve Yayın Etiğine Aykırı Eylemler" başlığı altında belirtilen eylemlerden hiçbirinin gerçekleştirilmediğini taahhüt ederiz.

\section{Kaynakça}

[1] Amstedter, B. L. 1971. Reliability Mathematics. McGraw-Hill, New York.

[2] Lewis, E. E. 1987. Introduction to Reliability Engineering. John Wiley \& Sons, Canada. 
[3] Shafer, S. M., Meredith, J. R. 1998. Operations Management. John Wiley \& Sons, New York.

[4] Bentley, J. P. 1993. An introduction to Reliability and Quality Engineering. Logman Scientific and Technical. John Wiley \& Sons, Inc, New York.

[5] Andrews, J. D., Moss, T. R. 2002. Reliability and Risk Assessment. Second Edition. Professional Engineering Publishing Limited: London and Bury St. Edmunds, UK, 540s.

[6] Hahn, G. J., Shapiro, S. S. 1967. Statistical Models in Engineering. John Wiley \& Sons, Inc. New York, Chichester, Brisbane, Toronto.

[7] Moss, T. R. 2005. The Reliability Data Handbook. Professional Engineering Publishing Limited: London and Bury St Edmunds, UK, 287s.

[8] Klein, J. 2003. Survival analysis: techniques for censored and truncated data. 2nd ed. New York, London: Springer.

[9] Li, W. 2004. Evaluating Mean Life of Power System Equipment with Limited End-of-Life Failure Data. IEEE Transactions on Power Systems, (18), 236-242.

[10] Maciejewski, H., Anders, G., Endrenyi, J. 2011. On the use of statistical methods and models for predicting the end of life of electric power equipment. International Conference on Power Engineering, Energy and Electrical Drives (POWERENG).

[11] Abernethy, R. 2006. The New Weibull Handbook. 5 th ed. Florida.

[12] Genschel, U., Meeker, W. 2010. A Comparison of Maximum Likelihood and Median-Rank Regression for Weibull Estimation. Quality Engineering, (22), 236-255.

[13] Olteanu, D., Freeman, L. 2010. The Evaluation of Median-Rank Regression and Maximum Likelihood Estimation Techniques for a TwoParameter Weibull Distribution. Quality Engineering, (22), 256-272.

[14] Abernethy, R. 2010. Discussion of the Papers by Olteanu and Freeman and Grenshel and Meeker. Quality Engineering, (22), 281-283.

[15] Zhou, D. 2013. Comparison of Two Popular Methods for Transformer Weibull Lifetime Modelling. International Journal of Advanced Research in electrical, Electronics and Instrumentation Engineering, 2(4), 2320-3765.

[16] Cacciari, M., Montanari, G. C. 1987. A method to Estimate the Weibull Parameters for
Progressively Censored Tests. IEEE Transaction on Reliability, (36), 87-93.

[17] Montanari, G. C., Mazzanti, G., Cacciari, M., Forhergill, J. C. 1997. Optimum Estimators for the Weibull Distribution of Censored Data. IEEE Transactions on Dielectrics and Electrical Insulation, (4), 462-469.

[18] Ng, H. K. T., Chan, P. S., Balakrishnan, N. 2004. Optimal Progressive Censoring Plans for the Weibull Distribution. Technometrics, (46), 470481.

[19] Zhang, L. F., Xie, M., Tang, L. C. 2006. Robust Regression using Probability Plots for Estimating the Weibull Shape Parameter. Quality and Reliability International, (22), 905-917.

[20] Boudt, K., Caliskan, D., Croux, C. 2011. Robust Explicit Estimators of Weibull Parameters. Metrika, (73), 187-209.

[21] Olteanu, D., Freeman, L. 2010. The Evaluation of Median-Rank Regression and Maximum Likelihood Estimation Techniques for a TwoParameter Weibull Distribution. Quality Engineering, (22), 256-272.

[22] Genschel, U., Meeker, W. Q. 2010. A Comparison of Maximum Likelihood and Median-Rank Regression for Weibull Estimation. Quality Engineering, (22), 236-255.

[23] Asgharzadeh, A., Valiollahi, R., Raqab, M. Z. 2011. Stress-strength Reliability of Weibull Distribution based on Progressively Censored Samples. SORT, (35), 103-124.

[24] Mohan, C. R., Rao, A. V., Anjaneyulu, G. V. S. R. 2013. Comparison of Least Square Estimators with Rank Regression Estimators of Weibull Distribution-A Simulation Study. Journal of Statistics, (20), 1-10.

[25] Lawson, C., Keats, J. B., Montgomery, D. C. 1997. Comparison of Robust and Least Squares Regression in Computer-Generated Probability Plots. IEEE Transactions on Reliability, 46(1), 108-121.

[26] Huber, P. J. 1981. Robust Statistics. John Wiley: New York.

[27] Hoaglin, D., Mosteller, F., Tukey, J. W. 1983. Understanding Robust and Exploratory Data Analysis. John Wiley \& Sons, Inc.: New York.

[28] Tobias, P. A., Trindade, D. C. 1995. Applied Reliability (Second Edition), Van Nostrand Reinhold.:New York. 